\title{
A normative theory of humanistic knowledge
}

Gregersen, Frans; Køppe, Simo

Published in:

Zeitschrift für allgemeine Wissenschaftstheorie

Publication date:

1989

Citation for published version (APA):

Gregersen, F., \& Køppe, S. (1989). A normative theory of humanistic knowledge. Zeitschrift für allgemeine Wissenschaftstheorie, 20(1), 40 - 53. 
A Normative Theory of Humanistic Knowledge

Author(s): Frans Gregersen and Simo Køppe

Source: Zeitschrift für allgemeine Wissenschaftstheorie / Journal for General Philosophy of Science, Bd. 20, H. 1 (1989), pp. 40-53

Published by: Springer

Stable URL: http://www.jstor.org/stable/25170828

Accessed: 10/02/2015 11:15

Your use of the JSTOR archive indicates your acceptance of the Terms \& Conditions of Use, available at http://www.jstor.org/page/info/about/policies/terms.jsp

JSTOR is a not-for-profit service that helps scholars, researchers, and students discover, use, and build upon a wide range of content in a trusted digital archive. We use information technology and tools to increase productivity and facilitate new forms of scholarship. For more information about JSTOR, please contact support@jstor.org. 


\title{
A Normative Theory of Humanistic Knowledge
}

\author{
FRANS GREGERSEN - SIMO KØPPE
}

\begin{abstract}
Zusammenfassung
Ausgehend von der Gegenüberstellung der Wissenschaftlichkeit der Naturwissenschaften und der Geisteswissenschaften wird argumentiert, daß Wissenschaftlichkeit nur auf der Basis einer Zusammenstellung wissenschaftstheoretischer, wissenschaftsgeschichtlicher und wissenschaftssoziologischer Kriterien definiert werden kann. Eine solche dreiteilige Definition wird skizziert, und es wird behauptet, daß dies gültig sowohl für die Naturwissenschaften als auch für die Geisteswissenschaften ist. Es folgt daraus, daß es im Prinzip keine Verschiedenheit zwischen der Wissenschaftlichkeit der einen Basiswissenschaft und der anderen gibt. Die Formulierung dreier normativer Kriterien für Wissenschaft als solche schließt den Artikel ab.
\end{abstract}

\section{INTRODUCTION ${ }^{1}$}

As researchers in the humanities we have lately been struck by the fact that strictly speaking we are impossible. Both to the public mind and to the philosopher of science a researcher is either a natural scientist or not at all. The interesting thing about this state of affairs is that it does not seem to bother anyone.

Now it might be argued that the recent crisis within philosophy of science is precisely concerned with the problem how to prove that there is a difference between science and pseudo-science. It has not until now been possible to reach an agreement on this socalled demarcation problem. And if we cannot show that the natural sciences are scientific, we humanists should not be sorry that we do not even qualify as worthy of attention in this respect.

This argument would, however, be beside the point in one important respect, viz. that it presupposes that the average scientist is influenced in his view by the philosopher of science. This is even less true for the public at large. The public and the average scientist whether he be a natural scientist or a humanist scientist all agree that science par excellence is natural science. This does not, to be sure, mean that the public think that the disciplines of history, psychology and linguistics, to name only some of the more prominent ones, are uninteresting or less valuable for society, than say chemistry. What it does mean is precisely that these disciplines are not scientific, they do not have any truth authority. ${ }^{2}$

1 The following article is a condensed version of some of the discussions elaborated in our book (Gregersen and Køppe 1985) about epistemology, history of science and sociology of science regarding humanistic science.

$2 \mathrm{By}$ and large the debate among the philosophers of science concern the natural sciences e.g. the implication of nuclear physics in general and quantum mechanics in particular for the specific theory of science that is on today's agenda. A note-worthy underlining of this situation can be 
Instead of immediately remediating this deplorable situation we might begin to speculate which interests are served by it and thus contribute to uphold it. It is a common observation that natural scientists think of humanists as creative and artistic $^{3}$, some of the natural scientists even propose to learn from the supposedly more intuitive way that the humanistic scientists create their knowledge. Still more common is the accepted myth of the logical natural scientist adding observation to observation until he finally reaches the appropriate generalization. These images of the typical natural and humanistic scientists are both of them miles apart form any reality, but the important thing is that they are miles apart from each others as well.

The natural scientist may long for the sides of his personality that the public thinks he has to suppress while all the way he can in practice use his creative talents and necessarily must use his intuition if he wants to produce new and daring conjectures or find new ingenious ways of refuting the old ones. The only condition is that he does not question the demarcation. Note that questioning the demarcation means at once questioning the possibility of distinguishing between humanistic and natural science and distinguishing between science and non-science, e.g. ideology or religious beliefs.

For the natural scientist the humanistic sciences are always quarrelling. Thomas S. Kuhn ${ }^{4}$ has acutely termed this continuous struggle for life a prerevolutionary stage, thus implying that normal scientists do not quarrel about fundamentals. Even if the picture of the humanistic sciences were true - which it is not - we would not be so frightened by it as Kuhn was. In fact, as Feyerabend has said ${ }^{5}$, it is the state of normal science which is a mortal illness. We shall return to this below, here it should be sufficient to remark that the obvious disagreement about fundamentals in the humanistic sciences may be used to obscure the wars between different paradigms in the natural sciences. And wars there have been.

The humanists seem content to be regarded as not quite scientific as long as they are not called upon to legitimate themselves. In times of crises - and everywhere in Europe that we know of (with the possible exception of the oil exporting state of Norway) the humanistic sciences are in a crisis - the humanists seem to have recourse not to their being true sciences, but to the ideology of romanticism and historicism. We shall argue below that the split between the humanistic sciences and the natural sciences was a consequence of the rise of ahistoric positivism within the natural sciences and historicist romanticism within the humanistic sciences. Nowhere can this descent of the bumaniora be seen as clearly as in the justification that the humanist departments choose to

seen in Blackwell (1983), a detailed bibliography of the philosophy of science in the period 1945-1981. Out of a total of 516 pages, 110 or approximately $20 \%$ concern special topics in the philosophy of the physical sciences, and 35 pages alone concern quantum mechanics.

${ }^{3}$ In the 1986 nobel laureate round table an impressive amount of time was spent on some natural scientist preaching the supposed merits of an artistic point of view. Natural scientists often confuse art and humanistic science.

4 T. S. Kuhn (1969).

5 P. Feyerabend (1970). 
use. Our experience is naturally limited, but the justifications produced by the Danish university departments all of them concern promises of a richer inner life for the students (in contradistinction to the technological advances that the natural sciences promise) and the preservation of the spiritual values of the nation state. The historians and students of the mother tongue join in their allegiance to the idea of the nation state. Compared to the hard cash we are promised by the sciences it is a tribute to the firm roots of the "Bildung" that it is so relatively successful as a pretext for having humanistic departments.

There is, of course, some truth in the various arguments based upon the idea of a close relation between humanistic studies and the socialization agencies (see part $\mathrm{V}$ below), but it cannot serve as a theory of science for the humanists that they have taken over the role of the church. At most it is a more or less accurate description of the function of the humanistic sciences. Consequently, we now take a closer look at the theory of science that has dominated the scene for the last 40 years, viz. the tradition of Popper. The purpose of the inspection is to see whether there might be themes in this tradition that could help towards establishing a normative theory of the humanistic sciences.

\section{PHILOSOPHY OF SCIENCE}

According to the mainstream of the philosophy of science, you may follow one of three strategies in defining scientific exploration. The first is to specify the epistemological conditions for obtaining true knowledge, thereby obtaining a logic for scientific discovery. Logical positivism is the primary advocate for this view, but it is also emphasized in Popper's critical rationalism. In the past 20-25 years a large number of studies in the history of sciences have shown that whatever epistemological criteria you choose to use, in fact, there have always been successful scientific theories which did not satisfy such epistemological criteria for true knowledge. ${ }^{6}$ The failure of the first strategy gave the impetus to a reformulation that emphasized two other strategies - the historical and the sociological. In spite of great differences between the three great philosophers of science of the post-Popperian periode, Kuhn, Lakatos and Feyerabend, they all of them agree in choosing the history of science and the sociology of science as their point of departure. A theory of science worth its name must fit the historical and sociological facts. Kuhn's paradigm as well as Lakatosian research programmes are historical concepts, and Paul Feyerabend exclusively uses the history of science when proposing his radical relativism. Kuhn', in particular, supports his theory of paradigms by a number of sociological theses regarding the sociological mechanism in groups of scientists, their publication channels, seminars, scientific education etc.

Philosophers of science who use the abovementioned strategies as foundations for defining scientific exploration presuppose, however, results from humanistic science. In most cases they do this without noticing it. Their theses tacitly imply rather complex theories about the perceiving subject, language,

6 The locus classicus is by now I. Lakatos (1970).

7 T. S. Kuhn (1968). 
history, and society. At the same time, they do not even recognize humanistic science as real science - the humanistic disciplines are said not to have reached that status yet. When the philosophers of science do underline some of the humanistic themes explicitly it is not very convincing. As an example we choose Feyerabend.

In one of his recent books ${ }^{8}$ Feyerabend tries to defend his radical relativism by the socalled principle of incommensurability, which states that not only you may not, you cannot compare two competing theories. Feyerabend bases this principle among other things on historical-anthropological theories regarding the historical development of the way human beings cognize reality, on the linguistic Sapir-Whorf hypothesis, and on the psychological theories of Jean Piaget, in particular his hypothesis regarding the psychological development of the child's perception of time and space. It is of course interesting for humanistic scientists that these themes "at last" get into the philosophical discussion of natural science, but on the other hand, the specific theories have been chosen without the slightest critique and discussion. Every historian knows that the way human beings cognize reality more or less is bound to their historical epoches, and the Sapir-Whorf hypothesis is frequently used to intensify the interests of the youngest students in humanistic sciences, but, and that is the important thing, all the three theories mentioned are debatable and debated and not just results, you can pick up without further ado. Actually, modern linguistics is based on the principle of translatability of all concepts, a principle, squarely at odds with the Sapir-Whorf thesis.

The point we wish to stress here is that you cannot on the one hand discuss the basic issues of philosophy of science ignoring humanistic science as science, and on the other hand, implicitly or without discussion use very complex hypotheses which are the specialties of the humanistic sciences, to construct the very theory of science that excludes the humanistic disciplines.

In our search for a theory of science that includes or specifies the humanistic disciplines we find ourselves with a theory of science that is in itself debatable and specifically presupposes that our problem has been solved. For if psychology is not scientific how could anyone build any theory on it?

\section{HERMENEUTICS}

Having reached this far in our text, some of our friends the philosophers might be so irritated as to exclaim "But there is a theory of science especially geared to the needs of the humanities, viz. bermeneutics".9

In this context we only want to discuss some important aspects of hermeneutic philosophy - aspects regarding the relations between the human subject and history, expecially how it is possible to conceptualize historical facts being yourself a historical subject.

8 P. Feyerabend (1975).

9 For a general discussion of hermeneutics see P. Ricoeur (1981) and the following references. It is noteworthy that Kuhn (1977) takes hermeneutics to be the historical-epistemological principle. 
According to the German philosopher W. Dilthey, the human subject is born into a specific culture, which determines his or her ways to acknowlege the world around him/her. This is also true when we reach out for scientific knowledge. Still, Dilthey maintained that it is possible for humanistic scientists to obtain objective knowledge. Dilthey claims that it is necessary to develop a bistorical consciousness by means of which it is possible to identify oneself with the tradition, thereby getting to be able to reconstruct the past. Historical consciousness is able to transcend the borders which are manifested by the specific culture which the scientific subject is immersed in.

Two other German hermeneutic philosophers - M. Heidegger ${ }^{10}$ and H.-G. Gadamer ${ }^{11}$ have criticized Dilthey precisely because of this view of the possibilities of objective humanistic knowledge. Heidegger claims that a human subject as such exists as being-in-the-world, and that the subject is bound to this world. One of the important characteristics of this ontological dimension is the socalled preunderstanding. Every one of us has basically and existentially an acknowledgement of the world we are born into, and it is completely impossible to transcend this dimension. Preunderstanding is especially important when in a scientific context we are confronted with cultural products and other human subjects.

H.-G. Gadamer has continued the tradition of Heidegger's hermeneutics. $\mathrm{He}$ underlines the importance of language as the medium in which we are bound to formulate our knowledge. Language is a specific cultural product, and it is not possible to filter out the historical determinants. This radical historicism leaves no room for a scientific process outside the determinants of history.

As far as we can see, if radical historicism is true, then it is true for all scientific disciplines, including the natural sciences. If the ontological dimension of hermeneutics is a primary condition for any subject, it must also include the natural scientist.

The conclusion is that hermeneutics is not able to constitute the foundation for humanistic science - either it is the foundation for all science or not a foundation at all.

This conclusion is not in harmony with recent philosophical theories which try to incorporate hermeneutics as a special branch for humanistic science. We think here of K.-O. Apel ${ }^{12}$, J. Habermas ${ }^{13}$ and G. Radnitzky. ${ }^{14}$ In spite of their differences, they all of them postulate that natural science and humanistic science are based on different principles, and claim, that the combination of these principles in the so called critical sciences is able to transcend the historical determinants. Our point is different, namely that it is impossible to base only humanistic science on hermeneutics, - either all sciences or none.

10 M. Heidegger (1962).

11 H.-G. Gadamer (1972).

12 K.-O. Apel (1967).

13 J. Habermas (1971).

14 G. Radnitzky (1968). 


\section{THREE PHILOSOPHICAL VIEWS ON SCIENCE AS SUCH}

Our main assumption is, that the only consistent definition of science has to include three fields: epistemology, history of science and sociology of science. The development in philosophy of science has shown, that it is impossible to define science from one of these criteria alone, without getting into serious troubles.

Assuming furthermore that the scientific universe may be divided into three basic types of research, natural science, social science and humanistics, it is immediately clear that they investigate different types of objects. Regarding this object-field of science, we may say, as a first abstraction, that natural science explores nature, social science prefers society and humanistic science takes as its object the subject as such and its cultural manifestations.

This generalization is so abstract, that its information value is close to zero. As a further generalization we suggest that humanistic sciences are concerned with four basic types of objects - the psychological subject, language, history and the arts. Every discipline within humanistic science - the national philologies, literary criticism, etc. ... - use hypotheses from the four basic humanistic fields of objects, often more than one at a time.

(a) Epistemology. One of the results of the development within philosophy of science is, that you no longer are able to define science purely from an epistemological point of view. The last 20-30 years can in this respect be labeled "the crisis of epistemology". It is a byproduct of this development that is at least our hypothesis - that it is no longer possible to draw a clearcut epistemological line between humanistic science and natural science. The objectivity of natural science and the subjectivity of human science are both of them a myth. In all science the choice of measuring-instruments not only delimit the field of objects, the instruments also interact with the object, and therefore determine the sort of knowledge you get. This interaction functions at very different levels, but the principle is the same. The interaction is, however, partly determined by the degree of reduction of the object. It is slightly easier to operationalize a phoneme than the semantics of the word "liberty" but it is part of the abovementioned myth, that you can eliminate interaction by reducing the object to directly measurable entities.

Reduction of the object to empirically testable entities is part of every science, also the humanistic. You can't explore the psychological subject scientifically if you try to investigate empirically e.g. "personality", "perception", "emotion" etc. as unreduced wholes - these are abstract concepts, which need reduction and operationalization, which is much the same thing, in order to be explorable. The point is, that you have to live with both sides of the problemreduction is necessary but the wholeness of the object is the only reality. If you lose the object as a whole in the scientific process you are no longer able to grasp the interaction between you yourself as a scientific subject and the object - you are no longer able to see the continutity between the motivated measurement and the object as such.

Epistemologically, humanistic science, (as all science), is characterized by a 
reduction of the object to empirically testable entities, the application of certain specified methods, the interaction between subject and object, and the need for reflection of the relations between reduction and wholeness of the object.

(b) History of science. History is relevant in at least two respects - as the history of the field of objects itself, and as the history of the reflections on the changing reality, in short as the history of science. The history of the field of objects is a question of the social character of this field - this will be dealt with below. When you want to define human science from the historical viewpoint, science is conceptualized as a structure of concepts subordinated to historical development.

The individual discipline within the field of humanistic science is constituted as a science at a certain time. This constitution happens as a so called epistemological rupture ${ }^{15}$ characterized by three simultaneous developments. (1) The particular field of objects of the individual discipline is established as the exclusive zone of interest for that particular discipline. (2) All previous discussions of themes relating to the field of objects are stigmatized as prescientific ideologies. From then on a structure of basic concepts which constitute the core of the particular science will develop. (3) The investigation of the field of objects is qualified by the introduction of certain specific methods. After the epistemological rupture, you are not able to choose the methods you like - not if the results are going to be valued as scientific.

The characteristics of epistemological rupture do not imply, that science as such is non-ideological. They mean, on the other hand, that the relation between the scientific results and ideology is of another kind than between ideology and the philosophical statements before the rupture. We here need to introduce a distinction between latent and manifest ideology, coined by the swedish philosopher Sven-Eric Liedman. ${ }^{16}$ In accordance with Liedman, we will define ideology as a coherent view of nature, human subject and society. This coherent view is not a distortion of some authentic, original true worldview - the point is, that every coherent totality-view of nature, subject and society is bound to be ideological. Every meaningful discourse has im- or explicitly an ideology. It does not need to be homogeneous, and if it is formulated explicitly, it always concerns but a part of the totality-view. Latent ideology is implicit while the partly explicated ideology is termed manifest.

In accordance with this definition, all scientific products - as meaningful discourse - are based on some latent ideology. Even in the most clearcut mathematical treatise you are in principle able to reveal latent ideology, especially if you see that particular treatise as part of a specific historical tradition. You can't "get rid of" ideology, only choose to pass it over in silence, or make it explicit.

If humanistic science often is more troubled by internal strife between diffe-

15 L. Althusser made this term, which he borrowed from Gaston Bachelard, famous in his lectures on marxism. (Althusser 1969).

16 S.-E. Liedman (1986). 
rent schools than natural science, it is not because human science is less scientific, but because the totality-view, in part owing to the practice of humanistic science, is more obvious. By "more obvious", we don't mean that facts from humanistic sciences are more ideological, than in other sciences, but only, that the ideological foundation is more explicit.

We have emphasized the epistemological dialectics between reduction and wholeness of the object. The ideological totality-view is basically a continuation of the passing from reduction to wholeness, - namely, a passing from wholeness to totality. The epistemological reduction of the object, and the ideological totalization are two apparently contradictory basic aspects of the scientific process, but equally inescapable. The only way out of this problem is to explicate the ideology, to analyze the relations between reduction and totalisation.

(c) Sociology of science. The epistemological rupture has important sociological corollaries. (Of course it might be possible to argue that the corollaries are causes and vice versa). Corresponding to the creation of a specific obligation to explore a certain object, we have the development of chairs at the universities and the rise of societies to promote the internal discussion among the new professionals. The rise of scientific societies is in its turn intimately linked to the development of journals and international congresses and meetings. In short what is most aptly described as a process of professionalization is at hand.

The professionalization process means of course that it is now possible to earn a living doing precisely what some persons earlier had done for part of their time as "amateurs". The founding fathers of the humanistic sciences had a rough start some of them precisely because as a rule they had to justify the new science as being a logical development of some old and established field of research while at the same time explicitly rejecting the established ways of conceptualizing the field. Revolutions always have their victims.

Professionalization presupposes the academy. Institutions like the academy function as socializing agencies for the future generation. Thomas $S$. Kuhn has in detail described the process of handing down the gospel: The paradigmatic text book becomes a classic and establishes the specific universe of discourse that in time will develop into an esoteric code of terms and concepts itself functioning as a rite de passage for the newcomers. Sometimes one might suspect that what is called theory is just an elaborated system of terminology. It is, in fact, not uncommon at the institutionalized rite de passage, the examinations, to meet with students who cannot understand that they did not pass the exam. - They knew all the terminology, could use all the correct words, so why didn't they pass? And indeed as the institutions grow older and the disciplines develop you will not even hear such complaints any longer because by now such students will pass!

The professional academy is a most ingenious and practical solution to the demarcation problem. Once you have entered the academy you have entered the privileged zone of truth. It will not bother the academy, if no two professors will agree on anything, the academy is not dogmatic about truth and there 
are many interesting views worth an academic discussion. Sociologically speaking, the demarcation problem was solved when the academy was institutionalized. The only discussions which involve practical reasoning on scientificity are the appointment discussions and these are internal to the academy.

\section{TOWARDS A DEFINITION OF THE HUMANISTIC SCIENCES}

After having introduced and discussed the necessity of using simultaneously the three ways of defining science as such, we want to take a step further by sketching how humanistic science was constituted as a separate scientific discipline.

Certainly the split between the different kinds of scientific disciplines is not a natural phenomenon which has been with us forever. It is difficult to locate the split precisely in time but one might begin by observing that after the speculative period of science called the enlightenment, it was not any longer the case that the prominent natural scientists were philosophers as well. Of course there have been and there will still be a lot of natural scientists who participitate in discussions on methodology and the theory of science but they do so from now on as natural scientists not as polyhistors. It is presumably important for the understanding of the process that the split occurred as historicism was born. The typical humanistic sciences like history (art history, history of literature, history of language), philology and philosophy were all deeply affected by the historicism of the $19^{\text {th }}$ century and probably the historical nature of the subject matter studied came to create a decisive difference between natural and humanistic sciences. The natural sciences study eternal laws, the humanistic sciences study historical phenomena.

But the historicist tradition does not and cannot now serve as a demarcation device since already in the beginning of this century the swiss linguist Ferdinand de Saussure (1857-1913) distinguished between synchrony and diachrony. ${ }^{17}$ Synchronic studies are systematic studies carried out on simultaneously existing units while diachrony consists in historical analysis. And historical analysis is itself a series of chronologically ordered synchronical analyses of succeeding stages. This distinction is by and large accepted by all humanistic sciences thus creating a justification for systematic humanistic studies of a non-historicist kind.

It is a commonplace of the history of science that positivism influenced all scientific activity deeply and that the social as well as the humanistic sciences tried to justify themselves by aping positivist methodology. Maybe psychology is the best example of this. It was constituted as a psycho-physics maintaining a strictly quantifiable methodology. But in 20-30 years both psychoanalysis and phenomenological psychology extended the borders for psychological science, thereby determining a more complex field of objects for scientific psychology, namely the psychological subject. But, as we are just going to show, - the elements of the field of objects of a specific scien-

17 In chap. 3 of F. de Saussure (1983). See also the discussion in M. Scheerer (1980). 
tific discipline are not always easy to locate in relation to the three main disciplines.

First strategy: A definition of the scientific activities based on the subject matter of research.

Consider a science such as psychology. Neuropsychologists study the human brain and so do neurologists, but the neurologist is normally seen as a natural scientist, the neuropsychologist would not necessarily want to be so classified. Or what about all the other branches of psychology that study for instance the effect of certain chemical substances on the psyche, the behaviour of rats in a laboratory and the simulation of intelligence by means of a computer. The first one investigates what doctors too would be interested in, the second one studies what the zoologist might as well study, and the last one overlaps in his interest with the computer scientist. And yet there is an increasing demand for a unified psychology, a conscious effort to fight the fragmentation into disciplines of what should have been a coherent theory of the human being's internal make up. The answer is simple one might say: Either psychology is not and can never be a unified science, all efforts notwithstanding, or if it is one and a unified science it is not a humanistic science.

This last option would have to be taken, if it was not possible to carry through exactly the same analysis for the other kernel sciences of the humanistic departments: Linguistics has through phonetics and neurolinguistics obvious connections with the natural sciences and via sociolinguistics and socialization theory close ties to the social sciences and yet we would want to keep as one science the science of language. Obviously, the same is true for archaeology and history. The conclusion is: It is not possible to separate the humanistic sciences from the two other main disciplines solely based on a scrutiny of the subject matter of science.

The conclusion as it stands is a negative one and it is, we believe, correct. Still, it does not preclude a delimitation of what the kernel sciences of the humanities take as their favorite point of departure, as their paradigmatic subject matter so to speak. As these central concerns for the humanities we have proposed the sciences of the subject, of history, and of language. As the last area we include aesthetics. There are certain internal connections between these four areas: History has - because of the central role of historicism in the establishment of the humanities - the unique position of being at once the all embracing total science of the humanities and a dimension, diachrony, in opposition to synchrony. Language plays a role in the formation of the subject and is more often than not, in the form of written texts, the very substance of history. As for psychology, the theory of the subject that implicitly or explicitly guides your research fundamentally shapes the type of history you will be able to write. Finally, both the theory of the subject and language (or rather the theory of sign systems) are fundamental to any conception of aesthetics, whether this be built on literature or any other sign system.

Accordingly, we find that this delimination may function as one of the building blocks in a definition of what the humanities are as sciences.

Second strategy: A definition using the history of science. 
We shall make this short. Obviously philosophy is the oldest of the sciences that now consider themselves humanistic. ${ }^{18}$ Next in line comes philology but it was not until historicism that the split between the natural, social and humanistic sciences was founded. And the split between the social and the humanistic sciences probably was aggravated when the social sciences took the natural sciences as their model as mentioned above.

The discipline of theology plays a special role in the history of the humanistic sciences. If we study the Realgeschichte of the universities, theology was of course the professional school in which what would now be called the humanities flourished. With the gradual secularization of Europe the humanities lost their immediate access to the people but that story is the next one to be told.

Third strategy: A definition using the type of practice the science aims at. The practice of the humanistic sciences is, we suggest, the socialization process. This makes the line of continuation from the vicars and priests of the periods when the church was the strongest ideological apparatus and to the highschool teachers and critics of today obvious.

The special relationship between schooling and the humanistic sciences becomes even clearer, when we remember that the cultural techniques of writing and reading are essentially humanistic. When the national states of Europe emerged and teaching reading began to be at the same time teaching the mother tongue, a need arose for the study of the mother tongue as a language on a par with latin and greek. The earliest attempts at linguistics were concentrated on grammar and only with romanticism do we find the epistemological rupture that created a science of language. Romanticism was of course also essential in furnishing the national languages of Europe with an ancient literature thus laying the foundations of the modern philologies.

Present day humanistic science is only connected with the practice that it has grown out of by countless links. But the chain is still there, ultimately the humanistic results end up in the schoolroom.

Fourth strategy: A definition based on the sociology of science.

Institutionally there seems to be universal agreement among university builders and planners that there is a difference between the departments of natural science and the arts-departments. The modern philologies and the arts seem to be the most stable components of the humanistic sciences, while history sometimes fuses with the social sciences and psychology sometimes remains apart. The buildings will typically contain immense libraries and a lot of copy machines or - what is now the equivalent - some computers that give access to data bases of relevance. On the other hand, there will typically be no laboratories, no machinery and consequently not the staffs of artisans, machinists and electricians that e.g. nuclear physics cannot do without. In short, the human sciences are thought of and practiced as "soft" qualitative science thereby

18 It is in fact arguable whether philosophy is one discipline any more. Philosophy of science has tended to develop into a branch of science and ethics and epistemology can perhaps only with difficulty be construed as disciplines irrespective of content. 
entering into a well known opposition that splits the social sciences internally while the natural sciences remain preoccupied with hard facts.

Taken apart neither of the strategies mentioned so far amounts to much but taken together and coordinated with the basic concepts from the preceding section, we might solve the somewhat artificial problem of defining the human sciences: The fields of objects are the arts, language, the subject and history. These fields were chosen in the process of founding the humanistic sciences, their particular epistemological rupture. The rupture was characterized by the thematic polarity between positivistic methodology (especially in psychology) at the one end, and historicism (especially in history and the national philologies) at the other, which, as we saw, already Saussure criticized with the concept of synchrony. Sociologically, the human sciences were upheld by and themselves contributed to a professionalization and specialization of the ideological socialisation, that resulted from the dissolution of religious Europe into secularized nation states with universal education. Psychology, in particular, functions as the scientific basis for pedagogical practices and the measurement of normality.

\section{A NORMATIVE BASIS FOR SCIENCE}

If we accept that the picture painted by the prejudiced natural scientist of an eternally quarrelling but extremely creative and artistic bumaniora is wrong, it is only with regret. As mentioned above we share Paul Feyerabend's conviction that the type of science that Thomas S. Kuhn has described as normal science is not a sign of sanity but a sign of decay. The particular historical period we have entered calls for a new strategy if we want to save truth-finding as a social phenomenon.

The irreversible specialization and the sociological solution of the demarcation problem have both of them removed the need for any scientist to partake in the dialogue on fundamentals that is absolutely necessary if the scientific community is to guarantee the truth of any particular theory. Instead of a continuing discussion across paradigms we see little discussion as such and absolutely no discussion between rivalling factions. This must be changed.

But before we can change it we have to agree on a set of rules by which the new game can be played. The demarcation problem is no longer an issue, the problem is how to evaluate a work of science. If we can agree on some norms for the quality of science we have taken an important step towards opening the interparadigmatic discussions. In short, instead of discussing whether a given theory is scientific or not, we should discuss whether it qualifies as good science or not.

In the following we suggest three characteristics of good science. Their particular realization will presumably reflect the different traditions and objects of the disciplines but in principle they should be valid for all kinds of science. We note in passing that the current change of scene within some of the more speculative natural sciences convince us that a parallel development is under way there.

The first characteristic is that good science realizes that its results as well as 
its concepts are historical phenomena. There is a growing interest in the history of science but the trend tends to split off the history of science from science as such, thus creating a situation where normal scientists can behave as if history has stopped. But history is not only the past but also the present and the future. In order to make discussions on the verisimilitude of results easier, every practising scientist should realize the historical nature of the discipline he is working within and the concepts he uses. In practice, this demand would take the form that every dissertation was required to sketch the history of the problem under investigation. Precise analysis of the historical nature of the problem under scrutiny will enable critical discussions to attack the ideological stance embodied in the actual research.

This first characteristic can be seen as a typical internal criterion. The second characteristic is typically external to the particular science within which the practitioner moves.

In a preceding section we sketched the necessary reduction the undivided material substance of the real world has to go through for it to be scientifically manageable. This reduction process is not normally visible as such but the characteristic we propose in this connection is that good science reflects upon this reduction process and its relation to the totality.

In practice, this normative demand may take two related forms: First the demand may legitimate interdisciplinary search for evidence from other supposedly independent disciplines for one's own insights. This is so, since several disciplines actually treat some of the same phenomena and so should at least converge in their findings. The other form is that it may lead to reflections on the role of the discipline in question in the totality of the scientific endeavour to understand the indivisible reality. If reduction is the sine qua non of scientificity simply because we cannot empirically investigate totalities as such, it becomes all the more important to realize that the reduction process is in principle arbitrary in being precisely a reduction. If we do not fulfill this demand we shall be painting simplistic portraits of tiny bits of the real cake and the portraits will even be incommensurable in the strict sense of that word.

The third characteristic of good science that we propose as a norm has to do with the relation to practice. Too many scientists have blindly followed what they believed to be their private fascination only to awake after the fact to discover that they have invented someting dreadful. Everyone will first and foremost think of the atomic bomb but we might just as well think of disastrous findings such as the IQ-test or the popular theories of congenital dyslexia. Anyone speculating on such topics should be forced to reflect upon what consequences their findings would have - forced by the norms of the scientific community that is.

As mentioned above every science has a preferred practice which it furnishes with substance. Consequently, it should be comparatively easy to establish as a norm that it is part of good scientific behaviour to relate one's findings to their imagined or real effects.

The three characteristics may be seen as a code for sound scientific conduct but it should be kept in mind that the code loses its raison d'être if it is not 
followed by the discussion it was constructed to facilitate. We feel that the current situation calls for an intensified effort towards establishing media and channels for this interdisciplinary and interparadigmatic discussion.

\section{BIBLIOGRAPHY}

Apel, Karl-Otto 1967: Analytic philosophy of language and the Geisteswissenschaften. DordrechtHolland.

Althusser, Louis 1969: For Marx. Allan Lane, London.

Blackwell, Richard J. 1983: A bibliography of the philosophy of science. 1945-81. Greenwood Press, London.

Feyerabend, Paul 1970: Consolations for the specialist. In Lakatos and Musgrave (eds.): Criticism and the growth of knowledge. Cambridge University Press, London 1970.

- 1975: Against method. Verso, London.

Gadamer, Hans-Georg 1972: Wabrbeit und Methode. J. C. B. Mohr, Tübingen.

Gregersen, Frans and Køppe, Simo 1985: Videnskab og lidenskab. Tiderne Skifter, København.

- 1988: Against epistemological relativism. Stud. Hist. Phil. Sci. vol 19, no. 4, pp. 447-487.

Habermas, Jürgen 1971: Knowledge and buman interests. Beacon Press, Boston.

Heidegger, Martin 1962: Being and time. Harper \& Row, London.

Kuhn, Thomas S. 1968: The relation between history and history of science. In The essential tension, University of Chicago Press, Chicago.

- 1969: The structure of scientific revolutions. The University of Chicago Press, Chicago.

- 1977: Preface to The essential tension, The University of Chicago Press, Chicago.

Lakatos, Imre 1970: Falsification and the methodology of scientific research programmes. In The methodology of scientific research programmes, pp. 8-101. Cambridge University Press, London.

Liedman, Sven-Eric 1986: Das Spiel der Gegensätze. Friedrich Engels Philosophie und die Wissenschaft des 19. Jabrhunderts. Campus, Frankfurt am Main.

Radnitzsky, Gerard 1968: Contemporary schools of metascience. Henry Regnery Company, Chicago.

Ricoeur, Paul 1981: Hermeneutics and the buman sciences. Cambridge University Press, New York.

Saussure, Ferdinand de 1983: Course in general linguistics. Translated by R. Harris. Duckworth, London.

Scheerer, Thomas 1980: Ferdinand de Saussure. Wissenschaftliche Buchgesellschaft. Frankfurt am Main.

Adresse der Autoren:

Frans Gregersen, Simo Køppe

Copenhagen University, Njalsgade 80, 2300 Copenhagen 5, Danmark 